\title{
Justifying conflicts of interest in medical journals: a very bad idea
}

A series of articles in the New England Journal of Medicine has questioned whether the conflict of interest movement has gone too far in its campaign to stop the drug industry influencing the medical profession. Here, three former senior NEJM editors respond with dismay

\section{Robert Steinbrook professor adjunct of internal medicine ${ }^{1}$, Jerome P Kassirer distinguished professor $^{2}$, Marcia Angell senior lecturer on social medicine ${ }^{3}$}

'Department of Internal Medicine, Yale School of Medicine, New Haven, CT 06520, USA; ${ }^{2}$ Tufts University School of Medicine, Boston, MA, USA; ${ }^{3}$ Harvard Medical School, Boston, MA, USA

A seriously flawed and inflammatory attack on conflict of interest policies and regulations appeared recently in a most unexpected location: the venerable and trusted New England Journal of Medicine (NEJM). In a series of rambling articles, one of the journal's national correspondents, Lisa Rosenbaum, supported by the editor in chief, Jeffrey Drazen, tried to rationalise financial conflicts of interest in the medical profession..$^{1-4}$ As former senior editors of the NEJM, we find it sad that the medical journal that first called attention to the problem of financial conflicts of interest among physicians would now backtrack so dramatically and indulge in personal attacks on those who disagree.

Physicians and the public rely on journals as unbiased and independent sources of information and to provide leadership to improve trust in medicine and the medical literature. Yet financial conflicts of interest have repeatedly eroded the credibility of both the medical profession and journals. ${ }^{56}$ As the Institute of Medicine explained in its 2009 report, a conflict of interest is "a set of circumstances that creates a risk that professional judgment or actions regarding a primary interest will be unduly influenced by a secondary interest." The key issue is that "a conflict of interest exists whether or not a particular individual or institution is actually influenced by the secondary interest." "7 The report drew heavily on a 1993 NEJM article by Dennis Thompson, not cited by Rosenbaum, which made clear that the rules "do not assume that most physicians or researchers let financial gain influence their judgment. They assume only that it is often difficult if not impossible to distinguish cases in which financial gain does have improper influence from those in which it does not."

The NEJM has now sought to reinterpret and downplay the importance of conflicts of interest in medicine by publishing articles that show little understanding of the meaning of the term. The concern is not whether physicians and researchers who receive industry money have been bought by the drug companies, as Drazen writes, ${ }^{4}$ or whether members of guideline panels or advisory committees to the US Food and Drug Administration with ties to industry make recommendations that are motivated by a desire for financial gain, as Rosenbaum writes. ${ }^{13}$ The essential issue is that it is impossible for editors and readers to know one way or the other. ${ }^{67}$

Judges are expected to recuse themselves from hearing a case in which there are concerns that they could benefit financially from the outcome. Journalists are expected not to write stories on topics in which they have a financial conflict of interest. The problem, obviously, is that their objectivity might be compromised, either consciously or unconsciously, and there would be no easy way to know whether it had been. Yet Rosenbaum and Drazen seem to think it is insulting to physicians and medical researchers to suggest that their judgment can be affected in the same way. Doctors might wish it were otherwise, but none of us is immune to human nature.

\section{Straw men}

Rosenbaum's language is colorful, but her arguments for the purported harms of conflict of interest policies and regulations are fanciful and data-free. No one is proposing that "we prevent the dissemination of expertise, thwart productive collaborations, or dissuade patients from taking effective drugs," or allow "true experts to be replaced—on advisory panels, as authors of reviews and commentaries, in other capacities of authority - by people whose key asset is being conflict-free." "Where is the evidence of "a loud chorus of shaming,", or "a stifling of honest discourse," ${ }^{2}$ or that "the license to trample the credibility of 
physicians with industry ties has silenced debate?"3 Silliness and fear mongering about straw men are masquerading as scholarly analysis.

In 2014, under the Open Payments program (the Physician Payment Sunshine Act which is part of the Affordable Care Act), the Centers for Medicare and Medicaid Services in the United States published 4.45 million financial transactions from healthcare industries to physicians and teaching hospitals over just the last five months of 2013; the total value was nearly $\$ 3.7 \mathrm{bn}$ (£2.4bn; €3.4bn). ${ }^{9}$ When full data for 2014 are reported later in 2015, the amounts may well exceed \$9bn. Drug and device companies are investor owned businesses that are required to maximize profits by any legal means. These companies are not charities, so they expect to get something in return for all the largesse; the evidence is that they do, and it is naive to explain the situation otherwise.

Put simply, financial conflicts of interest in medicine are not beneficial, despite strained attempts to justify them and to make a virtue of self interest. Unmistakably, collaborations between academia and industry can speed medical progress and benefit patients. Such partnerships, however, can flourish with far less money in aggregate flowing from drug and device manufacturers to physicians and their institutions, and without the web of other lucrative ties between industry and physicians that lack a clear scientific or medical purpose. There are few reasons for physicians and other investigators to have financial associations with industry other than research support and bona fide consulting related to specific research programs and projects. Physicians who develop products and hold patents or receive royalties should not evaluate the product. Other types of payments, such as speakers' and other personal fees, payments to be ghost authors of review articles, and ill defined consulting arrangements, distort physicians' work and undermine our independence, as has been repeatedly documented. And there are no excuses for outright gifts, such as meals, travel, lodging expenses, and entertainment.

\section{Editorial responsibility}

In 1984, the late Arnold S Relman, then the NEJM's editor in chief, instituted the first conflict of interest policy at any major medical journal. ${ }^{10}$ The policy required authors of research papers to disclose all financial ties they had to health industries, and if the ties were deemed significant they were published. In 1990, Relman extended the policy to prohibit authors of editorials and review articles from having any financial interest in a company (or its competitor) that was discussed in the article, since these types of manuscripts do not contain primary data but rely exclusively on the authors' judgment in citing and interpreting the literature. ${ }^{11}$ As Relman's successors, two of us (JPK and MA) continued these policies. We found that it was sometimes difficult, but nearly always possible, to find outstanding authors with the needed expertise and without a conflict of interest to write editorials and review articles. ${ }^{12}$ In 2002, however, after Drazen succeeded Angell, the policy was weakened, so that it only applied to authors with "any significant financial interest in a company (or its competitor) that makes a product discussed in the article."13 To its credit, The BMJ has taken the opposite approach and implemented a zero tolerance policy on educational articles by authors with industry ties. ${ }^{14}$

The privilege to serve as an editor of a major medical journal is accompanied by the responsibility to provide leadership on the critical issues that define the profession. How medicine responds to conflicts of interest and earns the trust of the larger society in which we exist is one such issue. In 1990, it was a bad idea for authors of editorials, review articles, and other opinion articles in medical journals to have financial conflicts of interest. A quarter of a century later, it is a very bad idea. The articles by Rosenbaum and the supportive editorial by Drazen could presage a further weakening of the conflict of interest policy at the $N E J M$, or they could serve as a wake-up call for all medical journals and the profession. It is time to move forward, not backward.

Competing interests: We have read and understood BMJ policy on declaration of interests and declare RS was deputy editor and national correspondent at NEJM and is now editor at large and viewpoints editor at JAMA Internal Medicine. JPK and MA were both editors in chief of NEJM.

Provenance and peer review: Commissioned; not externally peer reviewed.

1 Rosenbaum L. Reconnecting the dots $\square$ reinterpreting industry-physician relations. N Engl J Med 2015;372:1860-4.

2 Rosenbaum L. Understanding bias $\square$ the case for careful study. N Engl J Med 2015;372:1959-63.

3 Rosenbaum L. Beyond moral outrage weighing the trade-offs of $\mathrm{COI}$ regulation. N Engl J Med 2015;372:2064-8.

4 Drazen JM. Revisiting the commercial-academic interface. N Engl J Med 2015;372:1853-4.

5 Angell M. Drug companies and doctors: a story of corruption. New York Review of Books 2009 Jan 15. www.nybooks.com/articles/archives/2009/jan/15/drug-companies-doctorsastory-of-corruption.

6 Steinbrook R, Lo B. Medical journals and conflicts of interest. J Law Med Ethics 2012;40:3:488-99.

7 Lo B, Field MJ, eds. Conflict of interest in medical research, education, and practice. National Academies Press, 2009.

8 Thompson DF. Understanding financial conflicts of interest. N Engl J Med 1993;372:1853-4.

9 Department of Health and Human Services, Centers for Medicare and Medicaid Services. Annual report to Congress on the open payments program for fiscal year 2014. 2015. www.cms.gov/OpenPayments/Downloads/Open-Payments-April-2015-Report-to-Congress. pdf.

10 Relman AS. Dealing with conflicts of interest. N Engl J Med 1984;310:1182-3.

11 Relman AS. New information for authors $\square$ and readers. N Engl J Med 1990;323:56.

12 Kassirer JP. What the New England Journal of Medicine did. BMJ 2011;343:d5665.

13 Drazen JM, Curfman GD. Financial associations of authors. N Engl J Med 2002;346:1901-2.

14 Chew M, Brizzell C, Abbasi K, Godlee F. Medical journals and industry ties. BMJ 2014;349:97197.

Cite this as: BMJ 2015;350:h2942

๑ BMJ Publishing Group Ltd 2015 